\title{
LIXIVIAÇÃO DE METAIS PESADOS EM SOLOS TRATADOS COM LODO DE ESGOTO(1)
}

\author{
E. I. BERTONCINI(2) \& M. E. MATTIAZZO(3)
}

\begin{abstract}
RESUMO
Foi realizado um experimento em tubos de percolação, utilizando-se três solos, classi ficados como Areia Quartzosa (AQ), Latossolo Vermelho-Amarelo (LV) e Latossolo Vermelho-Escuro (LE), aos quais foram incorporadas sucessivas quantidades de lodo de esgoto, totalizando uma dose correspondente a 156,0 t ha-1 (base seca), num período de incubação de $\mathbf{3 1 0}$ dias. Após este período, os solos foram tratados com água ou com soluções de sais $\left(\mathrm{KCl}_{0,9} \mathrm{~mol} \mathrm{~L}^{-1}\right.$; $\mathrm{KNO}_{3} 0,9 \mathrm{~mol} \mathrm{~L}^{-1}$; $\mathrm{K}_{2} \mathrm{SO}_{4} 0,3 \mathrm{~mol} \mathrm{~L}^{-1}$ e $\left.\mathrm{Ca}\left(\mathrm{NO}_{3}\right)_{2} 0,3 \mathrm{~mol} \mathrm{~L}^{-1}\right)$, adicionadas em quantidade correspondente a quatro vezes a capacidade de retenção de água dos solos. No líquido percolado pela passagem das soluções salinas, foram determinadas as quantidades de $\mathrm{Cd}, \mathrm{Cr}, \mathrm{Cu}, \mathrm{Ni}$ e $\mathrm{Zn}$ presentes e, no percolado obtido com a passagem de água, além dos metais anteriormente citados, foram determi nadas também as quantidades de $\mathrm{Ca}^{2+}$ e $\mathrm{Mg}^{2+}$. Os resultados permitiram observar que a adição de $\mathrm{KCl}$ provocou o arraste de $5 \%$ do $\mathrm{Cd}$ adicionado via lodo aos solos $\mathrm{LV}$ e LE; para os outros sais utilizados e para a água, esse arraste nunca foi superior a $2 \%$ do metal pesado adicionado via lodo. A retenção de $\mathrm{Cd}, \mathrm{Cu}, \mathrm{Cr}$ e Ni aumentou com a elevação dos teores de óxidos de Fe e Al presentes nos solos. Os elevados valores de pH eo aumento no teor de matéria orgânica proporcionado pela adição de lodo refleti ram também na menor mobilidade dos metais. Os sais $\mathrm{KCl}$ e $\mathrm{K}_{2} \mathrm{SO}_{4}$ aumentaram a mobilidade de alguns dos metais estudados.
\end{abstract}

Termos de indexação: mobilidade, cádmio, cobre, crômio, níquel, zinco.

\footnotetext{
(1) Parte da Tese de Mestrado da primeira autora, apresentada ao Curso Pós-graduação em Solos e Nutrição de Plantas da Escola Superior de Agricultura "Luiz de Queiroz" - ESALQ /USP, Piracicaba (SP). Financiado pela FAPESP. Recebido para publicação em setembro de 1997 e aprovado em março de 1999.

(2) Doutoranda em Solos e Nutrição de Plantas, ESALQ/USP. CEP 13418-900 Piracicaba (SP). E-mail: eiberton@carpa.ciagri.usp.br.

(3) Professora Associada do Departamento de Química, ESALQ/USP. Caixa Postal 09, CEP 13418-900 Piracicaba (SP). E-mail: mmatiazo@carpa.ciagri.usp.br.
} 


\title{
SUMMARY: LEACHING OF HEAVY METALS IN SOILS AMENDED WITH SEWAGE SLUDGE
}

\begin{abstract}
This experiment was conducted in leaching tubes filled with soils classified as Typic Quartzipsament (AQ), Typic Hapludox (LV) and Rhodic Typic (LE). Sewage sludge was periodically added and incorporated to the soils in a total amount corresponding to $156,0 \mathrm{t} \mathrm{ha}^{-1}$ (dry weight basis), for an incubation period of 310 days. The soils were then treated with water and thefol lowing salt sol utions: $0.9 \mathrm{~mol} \mathrm{~L}^{-1} \mathrm{KCl} ; 0.9 \mathrm{~mol} \mathrm{~L}^{-1} \mathrm{KNO}_{3} ; 0.3 \mathrm{~mol} \mathrm{~L}^{-1} \mathrm{~K}_{2} \mathrm{SO}_{4}$ and $0.3 \mathrm{~mol} \mathrm{~L}-1 \mathrm{Ca}\left(\mathrm{NO}_{3}\right)_{2}$. Thewater and salt solutions wereadded in amounts corresponding to 4 times thewater retention capacity of thesoils. Thel eachatewas analyzed for $\mathrm{Cd}, \mathrm{Cr}, \mathrm{Cu}$, $\mathrm{Ni}$ and $\mathrm{Zn}$. In the percolateobtained with the water passage, $\mathrm{Ca}^{2+}$ and $\mathrm{Mg}^{2+}$ quantities were al so determined, besides those of the previousl y mentioned metals. Theresults showed that theaddition of $\mathrm{KCl}$ caused theleaching of $5 \%$ of the Cd added by sludgeto LV and LE soils. F or theother sal ts used and al so for water, the heavy metal leachate was bel ow $2 \%$. Thesoil retention of $\mathrm{Cd}, \mathrm{Cu}, \mathrm{Cr}$ and $\mathrm{Ni}$ increased with theincrease of thecontent of iron and al uminum oxi dein soils. Themovement of the heavy metals was al so decreased with theincrease of the soil pH and organic matter content, with the movement of somemetals increasing with the presence of the salts $\mathrm{KCl}$ and $\mathrm{K}_{2} \mathrm{SO}_{4}$.
\end{abstract}

Index terms: mobility, cadmium, copper, chromium, nickel, zinc.

\section{INTRODUÇÃO}

Num futuro próximo, o tratamento de esgotos deverá tornar-se uma prática rotineira no nosso País, em virtude da crescente pressão da sociedade pela despoluição dos rios e das previsões de escassez de água. Esse tratamento, qual quer que seja o processo utilizado, gera outro resíduo conhecido por lodo de esgoto ou biossólido, que, em função de sua origem, exclusi vamente doméstico ou doméstico eindustrial, pode conter metais pesados. Embora o uso desse resíduo no solo agrícola possa ser interessante pelo seu conteúdo em materiais orgânicos e nutrientes de plantas, a presença de metais pesados pode-se tornar motivo de preocupação em função da possibilidade de movimentação e conseqüente contaminação de camadas subsuperficiais do solo e águas subterrâneas por esses metais pesados.

Atributos do solo, tais como pH, teor de matéria orgânica, textura e composição das argilas, potencial redox, competição entre metais pelos sítios de adsorção, reações de complexação, temperatura e atividade microbiana foram citados por Lindsay (1979) como responsáveis pel o controle dos processos de degradação do conteúdo orgânico do resíduo e conseqüente solubilidade e mobilidade dos metais. Estudos de fracionamento de metais pesados real izados por Amaral Sobrinho et al . (1997) e Gomes et al. (1997) indicaram a importância dos óxidos de $\mathrm{Fe}$ e Al na retenção de metais, por meio de mecanismos de adsor ção específica e, ou, coprecipitação. Shuman (1985) observou que a adsorção de metais varia com o grau de cristalinidade dos óxidos deFeeAl presentes no sol o.
Assim, verificou que a CTC dos óxidos amorfos era 100 vezes maior que a dos óxidos cristalinos com possibilidade de adsorver 10 vezes mais metais do que as formas cristalinas.

Estudos sobre a movimentação de metais em solos tratados com lodo de esgoto sugerem que a quantidade de metais lixiviados, embora seja menor que $1 \%$ do total adicionado, pode el evar-se em solos arenosos, com baixos teores de matéria orgânica e sujeitos a chuvas intensas. Esses metais podem permanecer adsorvidos ou complexados até que mudanças ocorram no sistema (Schirado et al., 1986; Lamy et al., 1993; Taylor et al., 1995).

O comportamento de metais também é influenciado pela interação com outros cátions presentes no solo. Pavan et al. (1984), em experimentos com solos tratados com $\mathrm{CaSO}_{4}$, verificaram aumento no Ca trocável seguido de lixiviação de Mn e Al. Oates \& Caldwell (1985) encontraram aumento na lixiviação de $\mathrm{Mg}, \mathrm{K}, \mathrm{Na}$ e Mn após a aplicação de $\mathrm{CaSO}_{4}$. Zhu \& Alva (1993) observaram que, em solos neutros ou alcalinos, o transporte de Cu eZn para camadas mais profundas do sol ofoi relativamente baixo, porém o uso de $\mathrm{K}_{2} \mathrm{SO}_{4}$ aumentou o transporte daqueles metais, enquanto o uso de $\mathrm{CaSO}_{4} \mathrm{e} \mathrm{MgSO}_{4}$ minimizou o transporte de C orgânico dissolvidoe, conseqüentemente, de metais complexados por ligantes orgânicos.

A mobilidade de metais no solo pode ser acelerada em condições de campo pelo fluxo preferencial da solução do sol o no perfil, assim como pela formação de complexos facilmente transportáveis de metais e ligantes orgânicos. Para Dowdt et al. (1991) e 
Camobreco et al. (1996), dentre outros, estudos de laboratórios, em colunas de solos homogeneizados, talvez subestimem a mobilidade de metais devido ao transporte via fluxo preferencial.

O objetivo deste estudo foi avaliar não só a mobilidade de metais pesados em sol os de diferentes classes texturais, tratados sucessivamente com lodo de esgoto, mas também os efeitos da adição de sais na mobilidade desses cátions metálicos, tendo em vista que cátions e ânions presentes nesses sais poderão ser adicionados a solos tratados com lodo de esgoto como complemento da adubação.

\section{MATE RIAL E MÉTODOS}

\section{Solos}

Os solos utilizados no experimento foram Areia Quartzosa (AQ), Latossolo Vermel ho-Amarelo (LV) e Latossolo Vermel ho-Escuro (LE), coletados na camada de $0-20 \mathrm{~cm}$ de áreas cultivadas com canade-açúcar, da região de Piracicaba (SP). A caracterização física e o teor total de óxidos destes sol os encontram-se no quadro 1.

\section{Resíduo}

O lodo utilizado foi obtido na Estação de Tratamento de Esgotos da SABE SP em Barueri (SP). No tratamento do esgoto cru gerado na Grande São Paulo, essa estação utiliza digestão anaeróbica, seguindo-se adição de $\mathrm{FeCl}_{3}$ e cal para facilitar o processo de prensagem do resíduo tratado. A adição de cal faz com que o lodo produzido tenha um $\mathrm{pH}$ variando entre 10 e 12 . O lodo utilizado continha $70 \%$ de umi dade e $244,0 \mathrm{~g} \mathrm{~kg}^{-1}$ de carbono em média.

\section{Instalação e realização do experimento}

O experimento foi instalado em tubos de percol ação de $25 \mathrm{~cm}$ de altura e $10 \mathrm{~cm}$ de diâmetro, que apresentavam na base uma abertura protegida por uma tela fina de plástico conectada a uma mangueira flexível de $0,5 \mathrm{~cm}$ de diâmetro que permitia a condução do líquido percolado através do solo para recipiente col etor.
Na montagem dos tubos, foram utilizadas amostras dos sol os secas ao ar e passadas em peneira de $2 \mathrm{~mm}$ de abertura de malha. A quantidade colocada nos tubos foi suficiente para obter uma coluna de solo com altura de $20 \mathrm{~cm}(2.000,1.800 \mathrm{e}$ $1.900 \mathrm{~g}$ para $A Q, L V$ e LE, respectivamente). A primeira adição de lodo foi feita em quantidade correspondente a $27 \mathrm{t} \mathrm{ha}^{-1}$ (base seca). Após a incorporação do lodo ao solo, adicionou-se água deionizada nas quantidades de 150, 400 e $450 \mathrm{~mL}$ para os solos $A Q, L V$ e $L E$, respectivamente. $A$ quantidade de água foi determinada por meio de curvas características de retenção de sol ução no sol o pelo Método do Funil de Placa Porosa, descrito por Libardi (1995), e teve a finalidade de proporcionar condições de umidade para a degradação da carga orgânica do lodo pela mi crobiota do sol o sem permitir lixiviação. Durante o período de incubação, a umidade dos solos, tratados ou não com lodo, foi mantida por meio de adições periódicas de água deionizada.

Novas aplicações de lodo foram feitas aos 60 e 180 dias do início do experimento, em quantidades correspondentes a 54,0 e 75,0 t ha-1, respectivamente. Antes de cada nova incorporação de lodo, os solos contidos nos tubos eram retirados, secos ao ar e destorroados. Após esse preparo, era feita nova incorporação de lodo e, a seguir, os sol os tratados ou não eram retornados aos tubos. Esse procedimento era realizado com a finalidade de desagregar os grumos formados pelo lodo da aplicação anterior e homogeneizar a coluna de solo, uma vez que se observou a formação de canais preferenciais por onde a água escorria, impedindo a uniformi dade da frente de molhamento e favorecendo a lixiviação. A quantidade total de lodo de esgoto incorporada aos sol os foi correspondente a 156,0 t ha-1 (base seca).

O delineamento experimental empregado para incubação dos solos com lodo foi o inteiramente casualizado, com três repetições. Os tratamentos estudados consistiam em um esquema fatorial $3 \times 2$, para solos e doses de lodo (0 e 156 t ha-1), respectivamente.

As quantidades de metais adicionados aos solos, calculadas em função da composição quími ca do lodo, analisado segundo método descrito por Eaton et

Quadro 1. Características físicas e teor total de óxidos dos solos empregados no experimento

\begin{tabular}{|c|c|c|c|c|c|c|c|}
\hline Solo & Argila & Areia grossa & Areia fina & Silte & $\mathrm{Al}_{2} \mathrm{O}_{3}$ & $\mathrm{Fe}_{2} \mathrm{O}_{3}$ & $\mathrm{SiO}_{2}$ \\
\hline & & & & $\mathrm{g} \mathrm{kg}^{-1}$ & & & - \\
\hline $\mathrm{AQ}$ & 88 & 523 & 384 & 5 & 18 & 6 & 20 \\
\hline LV & 417 & 123 & 250 & 210 & 132 & 102 & 147 \\
\hline LE & 609 & 96 & 169 & 126 & 181 & 120 & 191 \\
\hline
\end{tabular}


al.(1995), e expressas, em $\mathrm{mg} \mathrm{kg}^{-1}$, foram de: $\mathrm{Cd}=$ 1,$7 ; \mathrm{Cr}=27,3 ; \mathrm{Cu}=48,9 ; \mathrm{Ni}=22,0$ e $\mathrm{Zn}=155,0$. As quantidades de $\mathrm{C}, \mathrm{N}, \mathrm{P}, \mathrm{K}, \mathrm{Ca}$ e Mg adicionadas, expressas, em $\mathrm{kg}^{-1}$ de solo, foram, respectivamente de: 15,$4 ; 1,7 ; 0,86 ; 0,08 ; 7,8$ e 95,8.

Após 310 dias de incubação, ou seja, 130 dias após a última aplicação de lodo, o sol o contido nos tubos foi amostrado e, nas amostras coletadas, foram feitas análises para avaliação da fertilidade segundo método proposto por Raij \& Quaggio (1983), com exceção do teor de $\mathrm{P}$ determinado em extrator Mehlich-1. A CTC dos solos foi obtida segundo método sugerido por Glória et al. (1965).

\section{Lixiviação dos solos contidos nos tubos com água deionizada}

Após o período de incubação dos sol os com lodo, procedeu-se à passagem de água deionizada pelos tubos de percolação, nas quantidades de 1.500, 2.200 e $2.500 \mathrm{~mL}$, respectivamente, para os sol os AQ, LV e LE, tratados ou não com lodo. A quantidade deágua adicionada correspondeu a quatro vezes a capacidade de retenção dos solos.

Para promover a lixiviação, os solos foram saturados lentamente posteriormente permitiu-se a passagem de mais líquido, através de um sistema com vazão controlada para $2 \mathrm{~mL} \mathrm{~min}^{-1}$. Aspecto do experimento de lixiviação é mostrado na figura 1.

A coleta de líquido percolado obtido de cada tratamento foi feita em frascos de $500 \mathrm{~mL}$ da seguinteforma: os $500 \mathrm{~mL}$ iniciais foram considerados como primeiro lixiviado, trocaram-se os frascos e coletaram-se os próximos $500 \mathrm{~mL}$ (segundo lixiviado), procedendo-se dessa forma até o terceiro lixiviado, com exceção dos tratamentos AQ e AQ + lodo, em que for am coletados apenas dois lixiviados, em virtude da menor quantidade deágua adicionada.

Obteve-se o volume de líquido percolado por pesagem. Nele foram determinados $\mathrm{Cu}, \mathrm{Cd}, \mathrm{Cr}, \mathrm{Ni}$, Zn e Mg por espectrometria de absorção atômica. A quantidade de Ca presente no lixiviado col etado foi obtida de acordo com método de Glória et al . (1964). Neste estudo, a variável analisada para avaliação do efeito dos tratamentos foi o teor total de metais lixiviados pelas três adições de água efetuadas nos tubos de percolação. Foi feita nova amostragem dos solos provenientes dos tratamentos após passagem de água deionizada e, nessas amostras, foi novamente avaliada a fertilidade.

O delineamento experimental adotado para a lixiviação dos solos com água foi inteiramento casual izado com três repetições no esquema fatorial $3 \times 2$ para solos e doses de lodo (0 e 156,0 t ha-1).

\section{Lixiviação das colunas de solo com as diferentes soluções salinas}

Nesta etapa, foram utilizados apenas os tubos de percolação que continham solo incubado com lodo. As sol uções sal inas usadas são citadas a seguir com a respectiva concentração, valores de pH e condutividade elétrica: $\mathrm{KCl}(0,9 \mathrm{~mol} \mathrm{L-1} ; 5,7$; $\left.79,5 \mathrm{mS} \mathrm{cm}^{-1}\right), \mathrm{KNO}_{3}\left(0,9 \mathrm{~mol} \mathrm{~L}^{-1} ; 5,6 ; 80,7 \mathrm{mS} \mathrm{cm}^{-1}\right)$, $\mathrm{K}_{2} \mathrm{SO}_{4}\left(0,3 \mathrm{~mol} \mathrm{~L}-1 ; 7,8 ; 53,2 \mathrm{mS} \mathrm{cm}^{-1}\right)$ e $\mathrm{Ca}\left(\mathrm{NO}_{3}\right)_{2}$ (0,3 mol L-1; 5,7; 34,0 $\left.\mathrm{mS} \mathrm{cm}^{-1}\right)$.

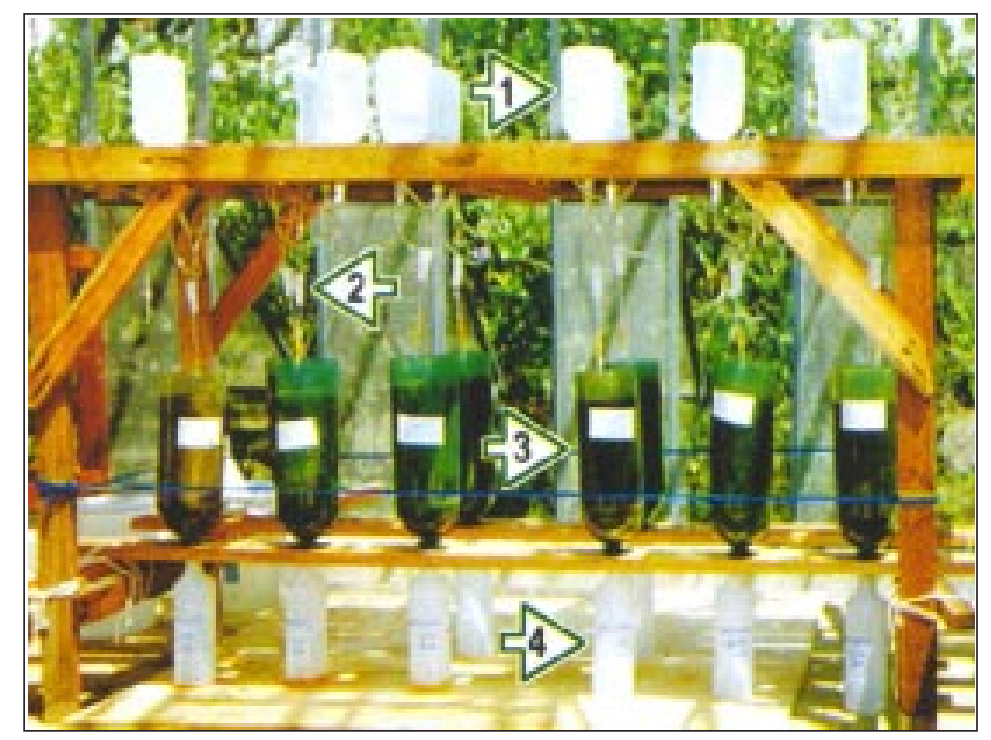

Figura 1. Aspecto do experimento para lixiviação de metais. (1) Frasco com solução percolante; (2) Mangueira com controle de vazão; (3) Tubo de percolação com os solos (testemunha e tratados com lodo); (4) F rasco coletor de lixiviado com capacidade para $500 \mathrm{~mL}$. 
Para cal cular a concentração das sol uções dos sais utilizadas, considerou-se que todas deveriam apresentar val ores idênti cos para a força iônica, bem como íons suficientes, em função da quantidade adicionada, para saturar a CTC dos sol os. O volume das soluções adicionadas aos solos, o procedimento adotado para a sua adição e as análises realizadas nos lixiviados coletados foram iguais aos utilizados na lixiviação com água.

O delineamento experimental adotado para a aval iação dos efeitos dos tratamentos foi inteiramento casual izado com três repetições no esquema fatorial $3 \times 5$ para sol os e soluções percolantes (quatro sais e água). Os teores de $\mathrm{Cd}, \mathrm{Cr}, \mathrm{Cu}, \mathrm{Ni}$ e $\mathrm{Zn}$ foram determinados nos lixiviados coletados por espectrofotometria de absorção atômica.

\section{RESULTADOS E DISCUSSÃO}

\section{Solos antes e depois da lixiviação com água}

A elevação no $\mathrm{pH}$ dos solos tratados com lodo (Quadro 2) pode ser atribuída principalmente à sua alcalinidadedoresíduo ( $\mathrm{pH}=11,0)$, a qual certamente sobrepuja os efeitos dos processos de degradação de materiais orgânicos que também contribuem para essa el evação (Mattiazzo \& Glória, 1987).

Levando-se em consideração que foram adicionados $15,4 \mathrm{~g} \mathrm{~kg}^{-1} \mathrm{de} C$ em todos os sol os, podese considerar observando-se exclusivamente o quadro 2, quea degradação do C-orgânico adicionado via lodo foi mais intensa nos sol os demaior fertilidade (LV e LE). Esta aparente diferença na vel ocidade de degradação de resíduos em solos de diferentes níveis de fertilidade foi também notada por Mattiazzo \& Glória (1987). Entretanto, após a passagem deágua pelos solos, houve remoção do $C$ presente em quantidadesuperior a $50 \%$ nos tratamentos com lodo (Quadro 3), sendo que as mai ores perdas ocorreram notratamento $A Q+L(68 \%)$, o queindica a presença de ácidos fúlvicos (C-orgânico solúvel em água).
Os valores determinados de CTC do solo (Quadro 2) foram maiores que os calculados pela soma de $\mathrm{K}+, \mathrm{Ca}^{2+}, \mathrm{Mg}^{2+} \mathrm{e} \mathrm{H}+\mathrm{Al}$, apesar da quantidade acumulada de sais nos solos tratados, o que parece indicar a necessidade de determinação direta da CTC em estudos que envolvem o uso de resíduos orgânicos em solos.

\section{Lixiviação com água e com soluções salinas dos metais presentes nas colunas de terra tratadas com lodo}

\section{Cádmio e Zinco}

Com exceção do $\mathrm{Cd}$ presente na solução de $\mathrm{KCl}$ percolada, não foi detectada a presença de $\mathrm{Cd}$ e Zn em nenhum lixiviado col etado, seja com as soluções salinas seja com água, o que indica a pequena mobilidade desses metais quando adi cionados a esses solos. Esse comportamento do Zn não foi o observado por Mattiazzo-Prezotto (1994), em estudo com diferentes solos em valores de pH inferiores a 5,5.

$\mathrm{Na}$ faixa de $\mathrm{pH}$ de solo $(6,5-7,5)$ observada neste experimento, os processos de preci pitação de Fee AI ocorrem com grande intensidade em função das baixas solubilidades de seus hidróxidos. Tais processos ocorrem, inicialmente, pela formação de núcleos primários, seguida de crescimento dos cristais pela adsorção de cátions aos sítios livres da superfície da micela e, dessa forma, pode haver oclusão dos metais que passam a ocupar uma posição fixa dentro do mineral (Ross, 1994). A contaminação do precipitado por íons solúveis nas condições de precipitação, denominada co-precipitação, é considerada por Amaral Sobrinho et al . (1997) como sendo responsável pela redução da solubilidade de Cd em experimentos de longa duração. Zhang et al . (1997) observaram que o zinco estava associado a formas amorfas de óxidos em sol os com $\mathrm{pH} \geq 6,9$.

Outra hipótese para a retenção do Cd e Zn em solos é dada por Ladonin \& Margolina (1997) que, estudando as interações deáci dos húmi cos e metais

Quadro 2. Características químicas dos solos após o período de incubação (310 dias) antes da lixiviação com água

\begin{tabular}{|c|c|c|c|c|c|c|c|c|c|c|}
\hline Tratamento $^{(1)}$ & $\mathrm{pH} \mathrm{CaCl}_{2}$ & C & $\mathbf{P}$ & $\mathbf{K}$ & $\mathrm{Ca}$ & Mg & Al & $\mathbf{H}+\mathbf{A l}$ & $\mathrm{CTC}^{(2)}$ & $\mathrm{CTC}^{(3)}$ \\
\hline & & $\mathrm{g} \mathrm{kg}^{-1}$ & $\mathrm{mg} \mathrm{kg}^{-1}$ & & & 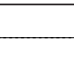 & $\mathrm{oll}_{\mathrm{c}}$ & & & - \\
\hline$A Q$ & 4,2 & 2,6 & 4,7 & 0,1 & 0,3 & 0,1 & 0,2 & 0,9 & 1,4 & 3,8 \\
\hline$A Q+L$ & 7,5 & 13,5 & 86,7 & 0,1 & 5,9 & 0,3 & 0,0 & 0,2 & 6,5 & 11,1 \\
\hline LV & 5,0 & 19,9 & 8,5 & 0,2 & 4,1 & 1,8 & 0,0 & 3,1 & 9,2 & 15,8 \\
\hline $\mathrm{LV}+\mathrm{L}$ & 6,8 & 21,9 & 74,7 & 0,3 & 15,7 & 1,5 & 0,0 & 0,2 & 17,7 & 23,0 \\
\hline LE & 4,0 & 13,1 & 8,1 & 0,1 & 0,5 & 0,2 & 1,5 & 4,8 & 5,6 & 10,1 \\
\hline$L E+L$ & 6,9 & 17,7 & 71,4 & 0,3 & 13,8 & 0,4 & 0,1 & 0,1 & 14,6 & 17,4 \\
\hline
\end{tabular}

(1) AQ, LV e LE referem-se às testemunhas e $\mathrm{H}$ aos mesmos sol os tratados com lodo de esgoto. ${ }^{(2)} \mathrm{CTC}$ cal culada. ${ }^{(3)} \mathrm{CTC}$ determinada (Glória et al., 1965). 
Quadro 3. Características químicas dos solos após a lixiviação com água

\begin{tabular}{|c|c|c|c|c|c|c|c|c|c|}
\hline Tratamento $^{(1)}$ & $\mathrm{pH} \mathrm{CaCl}{ }_{2}$ & C & $\mathbf{P}$ & $\mathbf{K}$ & $\mathrm{Ca}$ & Mg & Al & $\mathbf{H}+\mathbf{A l}$ & $\operatorname{CTC}^{(2)}$ \\
\hline & & $\mathrm{g} \mathrm{kg}^{-1}$ & $\mathrm{mg} \mathrm{kg}^{-1}$ & & . & $-\mathrm{cr}$ & & & - \\
\hline AQ & 4,3 & 1,3 & 4,1 & 0,0 & 0,2 & 0,1 & 0,2 & 0,2 & 0,5 \\
\hline$A Q+L$ & 6,3 & 4,3 & 66,2 & 0,0 & 2,3 & 0,3 & 0,0 & 0,2 & 2,8 \\
\hline LV & 5,1 & 11,8 & 3,5 & 0,2 & 2,4 & 1,3 & 0,2 & 3,1 & 7,0 \\
\hline$L V+L$ & 6,4 & 13,8 & 36,4 & 0,2 & 6,2 & 0,4 & 0,0 & 0,2 & 7,0 \\
\hline LE & 4,2 & 7,4 & 6,0 & 0,0 & 0,2 & 0,2 & 0,9 & 4,5 & 4,9 \\
\hline$L E+L$ & 6,2 & 9,9 & 31,4 & 0,1 & 5,3 & 0,3 & 0,2 & 0,4 & 6,1 \\
\hline
\end{tabular}

${ }^{(1)} \mathrm{AQ}$, LV e LE referem-se às testemunhas e $\mathrm{tL}$ aos mesmos solos tratados com lodo de esgoto. ${ }^{(2)} \mathrm{CTC}$ calculada.

pesados, demonstraram que a presença de cálcio em concentração menor que 0,5 mol L-1 reduz a adsorção deCd eZn. I sso se explica pel o fato de o cálcio ocupar as posições não específicas de troca, em detrimento daqueles metais. Todavia, a concentração el evada de Ca2+ também promove uma associação entre moléculas de ácido húmico, proporcionando o aumento da superfície ativa e o aparecimento de novos centros de adsorção, específica ou não, podendo, dessa forma, ocorrer adsorção, de Zn eCd. $\mathrm{O}$ aumento no $\mathrm{pH}$ do solo também favorece essa adsorção. A competição entre Cd, Zn e Cu por sítios ativos de ácidos húmicos ocorre somente quando a concentração desses compostos or gâni cos na solução do sol o é baixa (de 0,025 a 1,25 g L-1), sendo a ordem de compatibilidade e intensidade de adsorção a seguinte: $\mathrm{Cu}>\mathrm{Zn}>\mathrm{Cd}$. Em alta concentração de ácidos húmicos, esta ordem não se estabelece.

Nos percolados coletados dos solos LV e LE tratados com lodo e com solução de $\mathrm{KCl}$, notou-se a presença de $\mathrm{Cd}$ em quantidade correspondente a $5 \%$ dototal adicionado, podendo ser atribuída à formação de clorocomplexos de $\mathrm{Cd}$ que, segundo Tills \& Alloway (1983), aumentam deimportância emfunção do aumento da concentração de $\mathrm{Cl}^{-}$no meio. Pode ser atribuída, também, à formação de complexos sol úveis de Cd com a matéria orgânica, que ocorre com três a $12 \%$ do elemento adicionado na faixa de $\mathrm{pH}$ de 5,0 a 7,0 (Lamy et al., 1993), queéa faixa depH observada no LV e LE tratados com lodo. A presença do cátion monovalente $\left(\mathrm{K}^{+}\right)$em alta concentração favorece a dispersão de materiais orgânicos, liberando o Cd para a formação de cl orocomplexos solúveis (Doner, 1978; Zhu \& Alva 1993).

\section{Crômio}

Não foi detectada a presença de $\mathrm{Cr}$ na água deionizada percolada através dos solos, indicando que o metal adicionado foi fortementeretido. Apenas no tratamento $A Q+L$, quando se coletou lixiviado através da passagem de solução de $\mathrm{KCl}$, foi encontrada a quantidade $0,3 \mathrm{mg} \mathrm{L}-1$ de $\mathrm{Cr}$, o que corresponde a $0,3 \%$ do $\mathrm{Cr}$ adicionado ao solo através do lodo de esgoto, evidenciando o efeito desse sal sobre a mobilidade do elemento.

\section{Cobre}

A passagem de água deionizada pelos solos provocou o arraste do Cu presente nos tratamentos com lodo, com exceção do tratamento LE + L (Quadro 4), que é o solo com maior conteúdo de óxidos. As maiores quantidades de $\mathrm{Cu}$ foram detectadas nos lixiviados obtidos no sol oarenoso com menor conteúdo de óxidos e menor CTC. Nesse solo, também foram observadas as maiores perdas de C orgânico pela lixiviação, refletindo a formação de complexos orgânicos solúveis de Cu. O uso da solução de $\mathrm{K}_{2} \mathrm{SO}_{4}$ favoreceu a presença de $\mathrm{Cu}$ no lixiviado. De acordo com Zhu \& Alva (1993), o íon K+ promove a dispersão de compostos orgânicos aos quais o Cu encontra-se preferencialmente ligado, e a formação dos pares iônicos $\mathrm{CuSO}_{4}$ e $\mathrm{CaSO}_{4}$ pode explicar a maior remoção de $\mathrm{Cu}$ com o uso dessa solução. Entretanto, apesar de observada, a quantidade do elemento encontrada nos lixiviados nunca foi superior a $1 \%$ do total adicionado.

Nos lixiviados coletados pela passagem das soluções $\mathrm{KCl}$ e $\mathrm{KNO}_{3}$, a presença de C orgânico foi evidenciada pela sua col oração escura. Nos lixiviados com K $\mathrm{SO}_{4}$, além da presença de $\mathrm{C}$ orgânico, notouse $\mathrm{CaSO}_{4}$ precipitado, indicando a intensa troca iônica entreo $\mathrm{K}+$ adicionado e o $\mathrm{Ca}^{2}+$ presente no solo.

\section{Níquel}

A presença de $\mathrm{Ni}$ foi observada no líquido percolado dotratamento $A Q+L$, independentemente do uso da água ou das solução salinas. Nesse tratamento, apenas o $\mathrm{Ni}$ foi o el emento presente em mai or quantidade, só sendo superado pelo $\mathrm{Ca}$ e Mg. Anal isando os sais utilizados, verificou-se que ${ }_{2} \mathrm{SO}_{4}$ e $\mathrm{KCl}$ provocaram maior arraste do elemento, respectivamente, de 1,9 e 1,6\% do total adicionado (Quadro 5). A lixiviação de Ni pel o uso da sol ução de $\mathrm{KCl}$ pode ser devida à formação de clorocomplexos de Ni. Doner (1978), realizando estudo em colunas de solo, verificou a mobilidade de $\mathrm{Ni}$ na presença de soluções de cloreto e perclorato de sódio, em razão da alta constante de estabilidade apresentada pelo clorocomplexo do metal, que propiciam a formação e mobilidade do complexo formado. A possibilidade 
Quadro 4. Quantidade de Cu lixiviado com diversas soluções e \%de Cu lixiviado em relação ao total adicionado. Média de três repetições ${ }^{(1)}$

\begin{tabular}{lllllll}
\hline Tratamento $^{(2)}$ & Água & $\mathbf{K C l}$ & $\mathbf{K N O}_{\mathbf{3}}$ & $\mathbf{K}_{\mathbf{2}} \mathbf{S O}_{\mathbf{4}}$ & $\mathbf{C a}\left(\mathbf{N O}_{\mathbf{3}} \mathbf{2}_{\mathbf{2}}\right.$ \\
\hline & \multicolumn{5}{c}{$\mathrm{mg} \mathrm{L}^{-1}$} \\
\cline { 2 - 6 } $\mathrm{AQ}+\mathrm{L}$ & $1,0 \mathrm{c}$ & $1,1 \mathrm{bc}$ & $1,4 \mathrm{~b}$ & $1,7 \mathrm{a}$ & $1,1 \mathrm{bc}$ \\
$\%$ do adicionado & 0,5 & 0,7 & 0,8 & 1,0 & 0,6 \\
$\mathrm{LV}+\mathrm{L}$ & $0,3 \mathrm{c}$ & $0,9 \mathrm{a}$ & $0,6 \mathrm{~b}$ & $1,1 \mathrm{a}$ & $0,3 \mathrm{c}$ \\
$\%$ do adicionado & 0,2 & 0,5 & 0,4 & 0,7 & 0,2 \\
LE + L & $0,0 \mathrm{~d}$ & $0,9 \mathrm{a}$ & $0,6 \mathrm{~b}$ & $0,7 \mathrm{ab}$ & $0,3 \mathrm{c}$ \\
$\%$ do adicionado & 0,0 & 0,6 & 0,4 & 0,5 & 0,2 \\
C.V. $=13,39 \%$ & & & & &
\end{tabular}

(1) Médias seguidas de mesma letra, na horizontal, não diferem entre si (Tukey 5\%). (2) AQ, LV e LE referem-se às testemunhas e $+\mathrm{L}$ referem-se aos solos tratados com lodo.

Quadro 5. Quantidade de Ni lixiviado no tratamento $A Q+L$ com diversas soluções e \% de $\mathrm{Ni}$ lixiviado em relação ao total adicionado. Média de três repetições ${ }^{(1)}$

\begin{tabular}{|c|c|c|c|c|c|}
\hline Tratamento & Água & $\mathrm{KCl}$ & $\mathrm{KNO}_{3}$ & $\mathrm{~K}_{2} \mathrm{SO}_{4}$ & $\mathrm{Ca}\left(\mathrm{NO}_{3}\right)_{2}$ \\
\hline & 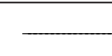 & 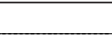 & $-\mathrm{mg} \mathrm{L}^{-1}$ & & - \\
\hline $\begin{array}{l}A Q+L^{(2)} \\
\% \text { do adicionado }\end{array}$ & $\begin{array}{l}1,0 \mathrm{bc} \\
1,1\end{array}$ & $\begin{array}{l}1,4 \mathrm{ab} \\
1,6\end{array}$ & $\begin{array}{l}0,8 \mathrm{c} \\
1,0\end{array}$ & $\begin{array}{l}1,6 \text { a } \\
1,9\end{array}$ & $\begin{array}{l}0,7 \mathrm{c} \\
0,8\end{array}$ \\
\hline C.V. $=14,7 \%$ & & & & & \\
\hline
\end{tabular}

de formação de pares iônicos entre $\mathrm{Ni}$ e $\mathrm{SO}_{4}^{2-}$ pode explicar a movimentação do el emento provocada pela adição da solução de $\mathrm{K}_{2} \mathrm{SO}_{4}$. Não foi detectada a presença de $\mathrm{Ni}$ nos lixiviados coletados dos tratamentos $L V+L$ e $L E+L$. Experimentos realizados por Gomes et al . (1997); Wang et al . (1997) e Amaral Sobrinho et al. (1997), em solos tratados com sais ou resíduos diversos, revelaram que o $\mathrm{Ni}$ tem sido encontrado preferencialmente na fração residual e ocluído junto aos óxidos de Fe eAI, eque, quanto maior o tempo de incubação desse el emento no solo, mai or é a fração que aparece ligada à forma residual. I sto talvez possa explicar a ausência de $\mathrm{Ni}$ nos lixiviados col etados naqueles tratamentos cujos solos são de textura fina e apresentam elevados teores de óxidos.

\section{Lixiviação com água do cálcio e magnésio nas colunas de terra tratadas ou não com lodo}

A presença de Ca foi observada no líquido percolado de todos os solos estudados, tratados ou não com lodo (Quadro 6). N os tratamentos LV e LE com lodo, a lixiviação com água promoveu, respectivamente, uma remoção de 19,0 e 17,9\% do total de Ca presente no solos, ou seja, a quantidade fornecida pelo lodo somada à que existia originalmente no solo. É provável que a adsorção específica de íons divalentes na superfície dos óxidos desses sol os não tenha sido suficiente para reter todo o cálcio adicionado através do lodo.

A quantidade de Mg presente nos lixiviados após a adição de água aos sol os testemunha evidencia a baixa retenção desse elemento (Quadro 6). Com a adição de lodo, observa-se comportamento diferente nos solos utilizados. Nos tratamentos AQ e LE, observou-se aumento na retenção do Mg com adição de lodo e esta não se alterou no LV.

Quadro 6. Quantidades de Ca e Mg presentes nos lixiviados com água e \% de Ca e Mg lixiviados em relação ao trocável do solo e ao total adicionado via lodo. Média de três repetições ${ }^{(1)}$

\begin{tabular}{|c|c|c|c|c|}
\hline \multirow{2}{*}{ Tratamento(2) } & \multicolumn{2}{|r|}{$\mathrm{Ca}$} & \multicolumn{2}{|r|}{ Mg } \\
\hline & Lixiviado & \% do trocável(3) e do total(4) & Lixiviado & \% do trocável(3) e do total(4) \\
\hline & $\mathrm{mg} \mathrm{L}^{-1}$ & & $\mathrm{mg} \mathrm{L}^{-1}$ & \\
\hline $\begin{array}{l}\text { AQ } \\
\text { LV } \\
\text { LE }\end{array}$ & $\begin{array}{l}1,2 \mathrm{~b} \\
4,2 \mathrm{a} \\
1,2 \mathrm{~b}\end{array}$ & $\begin{array}{l}10,5 \\
13,9 \\
13,1\end{array}$ & $\begin{array}{l}0,5 \mathrm{~b} \\
1,3 \mathrm{a} \\
0,2 \mathrm{~b}\end{array}$ & $\begin{array}{l}21,6 \\
20,5 \\
16,7\end{array}$ \\
\hline C.V. (\%) & 8,8 & & 25,0 & \\
\hline $\begin{array}{l}A Q+L \\
L V+L \\
L E+L\end{array}$ & $\begin{array}{l}2.643,3 \mathrm{~b} \\
5.051,0 \mathrm{a} \\
3.624,0 \mathrm{ab}\end{array}$ & $\begin{array}{l}13,4 \\
19,0 \\
17,9\end{array}$ & $\begin{array}{r}34,0 \mathrm{~b} \\
337,0 \mathrm{a} \\
53,5 \mathrm{~b}\end{array}$ & $\begin{array}{r}8,9 \\
20,4 \\
10,8\end{array}$ \\
\hline C.V. (\%) & 23,0 & & 51,0 & \\
\hline
\end{tabular}

(1) Médias seguidas de mesma letra, na vertical, não diferem entre si (Tukey 5\%). (2) AQ, LV e LE referem-se às testemunhas e $H$ referem-se aos solos tratados com lodo. ${ }^{(3)}$ Calculado com base no trocável presente no solo e o presente no lixiviado col etado da testemunha. ${ }^{(4)}$ Calculado com base no trocável +o adicionado pel o lodo e o presente no lixiviado col etado dos tratamentos com lodo. 
Nota-se o alto coeficiente de variação apresentado nas determinações de Mg por meio da espectrometria de absorção atômica, provavel mente devido a erros adicionais causados pela necessi dade de sefazer uma ou mais etapas de diluição, tendo em vista a faixa ótima do método analítico. $A$ adoção do método titulométrico do EDTA, também utilizado na determinação do cálcio (Glória et al., 1964), talvez fosse o mais indicado no presente estudo.

\section{CONCLUSÕES}

1. Os sais $\mathrm{KCl}$ e $\mathrm{K}_{2} \mathrm{SO}_{4}$ tiveram efeito na mobilidade dos metais $\mathrm{Cd}, \mathrm{Cr}, \mathrm{Cu}$ e $\mathrm{Ni}$, porém essa mobilidade esteve sempre abaixo de $2 \%$ do total adicionado, o que indica quea adição de fertilizantes que contêm cátions monoval entes eânions $\mathrm{Cl}-\mathrm{eSO}_{4}{ }^{2}$, utilizados para complementar a fertilização, deveser também motivo de preocupação quando do uso de resíduos que contêm aqueles metais.

2. A retenção de $\mathrm{Cd}, \mathrm{Cu}, \mathrm{Cr}$ e Ni aumentou com a elevação nos teores de Fe dos solos, indicando sua contribuição na retenção de metais.

3. Os el evados val ores de $\mathrm{pH}$ eo aumento no teor de matéria orgânica proporcionado pela adição do lodo contribuíram para a menor mobilidade de metais.

\section{LITERATURA CITADA}

AMARAL SOBRINHO, N.M.B.; VELLOSO, A.C.X. \& OLIVEIRA, C. Solubilidade de metais pesados em solo tratado com resíduo siderúrgico. R. Bras. Ci. Solo, 21:9-16, 1997.

CAMOBRECO, V.J .; RICHARDS, B.K.; STEENHUIS, T.S.; PEVERLY, J.H. \& MC BRIDE, M.B. Movement of heavy metals through undisturbed and homogenized soil columns. Soil Sci., 161:740-750, 1996.

DONER, H.E. Chlorideas a factor in mobilities of Ni (II), Cu (II), and Cd (II) in soil. Soil Sci. Soc. Am. J ., 42:882-885, 1978.

DOWDT, R.H.; LATTERELL, J . . .; HINESLY, T.D.; GROSSMAN, R.B. \& SULLIVAN, D.L. Trace metal movement in an Aeric Ochraqualf following 14 years of annual sludge applications. J . Environ. Qual., 20:119-123, 1991.

EATON, A.D.; CLESCERI, L.S. \& GREENBERG, A.E. Standards Methods for the examination of water and wastewater. 19.ed. Washington, D.C, American Public Health Association, 1995. Paginação irregular.

GLÓRIA, N.A.; CATANI, R.A. \& MATUO, T. Método doEDTA na determinação do cálcio e mágnesio "trocável" do solo. An. ESALQ, 21:218-228, 1964.

GLÓRIA, N.A.; CATANI, R.A. \& MATUO, T. A determinação da capacidade de troca de cátions do sol o pel o método do EDTA. R. Agric., 40:193-198, 1965.
GOMES, P.C.; FONTES, M.P.F.; COSTA, L.M. \& MENDONÇA, E.S. Extração fracionada de metais pesados em Latossolo Vermelho-Amarelo. R. Bras. Ci. Solo, 21:543-551, 1997.

LADONIN, D.V. \& MARGOLINA, S.E. Interaction betwen humic acids and heavy metals. Eurasian Soil Sci., 30:710-715, 1997.

LAMY, I.; BOURGEOIS, S. \& BERMOND, A. Soil cadmium mobility as a consequence of sewage disposal. J . Environ. Qual., 22:731-737, 1993.

LIBARDI, P.L. Dinâmica da água no solo. Piracicaba, Editado pelo Autor, 1995. 497p.

LINDSAY, W. L. Chemical equilibria in soils. New York, J ohn Wiley \& Sons, 1979. 449p.

MATTIAZZO, M.E. \& GLÓRIA, N.A. Effect of vinasse on soil acidity. Water Sci. Tecnol., 19:1293-96, 1987.

MATTIAZZO-PREZOTTO, M.E. Comportamento de Cu, Cd, Cr, $\mathrm{Ni}$ e $\mathrm{Zn}$ adicionados à solos de clima tropical em diferentes valores de pH. Piracicaba, Escola Superior de Agricultura "Luiz de Queiroz", 1994. 197p. (Tese de Livre Docência)

OATES, K.M . \& CALDWELL, A.G. Use of by product gypsum to alleviate soil acidity. Soil Sci. Soc. Am. J ., 49:915-918, 1985.

PAVAN, M.A.; BINGHAM, F.T. \& PRATT, P.F. Redistribution of exchangeable calcium, magnesium, and aluminium following lime or gypsium aplications to a Brazilian Oxisol. Soil Sci. Soc. Am. J ., 48:33-38, 1984.

RAIJ , B. van \& QUAGGIO, J .A. Métodos de análise de solo para fins de fertilidade.Campinas, Instituto Agronômico, 1983. (Bol etim Técnico, 81)

ROSS, S.M. Toxic metals in soil-plant-systems. New York, J ohn Wiley \& Sons, 1994. 469p.

SCHIRADO, T.; VERGARA, I.; SCHALSCHA, E.B. \& PRATT, P.F . Evidence for movement of heavy metals in a soil irrigated with untreated wastewater. J . Environ. Qual., 15:9-12, 1986.

SHUMAN, L.M. Fractionation method for soil microelements. Soil Sci., 140:11-22, 1985.

TAYLOR, R.W.; XIU, H.; MEHADI, A.A.; SHUFORD, J.W. \& TADESSE, W. Fractionation of residual cadmium, copper, nickel, lead, and zinc in previously sludge-amended soil. Comm. Soil Sci. Plant Anal., 26:2193-2204, 1995.

TILLS, A.R. \& ALLOWAY, B.J . The use of liquid chromatography in the study of cadmium speciation in soils solutions from poluted soils. J. Soil Sci., 34:769-81, 1983.

WANG, P.; QU, E.; ZHENBIN, L. \& SHUMAN, L.M. Fractions and availability of nickel in loessial soil amended with sewage or sewage sludge. J. Environ. Qual., 26:795-801, 1997.

ZHANG, M.; ALVA, A.K.; LI, Y.C. \& CALVERT, D.V. Chemical association of $\mathrm{Cu}, \mathrm{Zn}, \mathrm{Mn}$, and $\mathrm{Pb}$ in selected sandy citrus soils. Soil Sci., 162:181-188, 1997.

ZHU, B. \& ALVA, A.K. Trace metal and cation transport in a sandy soil with various amendments. Soil Sci. Soc. Am. J ., 57:723-727, 1993. 